\title{
TEATRO DA PÓS-MIGRAÇÃO: HISTÓRIA DAS PERSPECTIVAS ALEMÃ-TURCA
}

\author{
Barbara Kastner \\ Teatro, Cinema e TV na Freie Universität de Berlim \\ Comunicação na Technische Universität de Berlim \\ Mestre em Ciência do Teatro e Comunicação na Freie Universität de Berlim \\ E-mail: barbkastner@gmx.de
}

Após o fim da segunda guerra, a falta de mão de obra na Alemanha leva a acordos de migração com diferentes países para ocupação de postos de trabalho. Um grande contingente de migrantes provinha da Turquia. Nos anos 1950 e 60 a produção cultural turca não era perceptível pela sociedade alemã, mas surge aos poucos, nos anos subsequentes, em cabarets e filmes. A partir dos anos 1980 o teatro começa abordar a temática do migrante, mas sobretudo tratando do contexto sócio-cultural. $O$ teatro juvenil abordava o tema da migração com clichês relativos à religião e à criminalidade juvenil. Só em 2008, quando Shermin Langhoff assumiu o teatro Ballhaus Naunynstrasse, em Berlim, o teatro passa a retratar a realidade social da Alemanha como país de imigração: os hábitos culturais do público e os pontos de vista convencionais são questionados por diretores e diretoras pós-migrantes, frequentemente já na terceira geração na Alemanha. Lentamente, o teatro profissional alemão se abre também para dramaturgos e atores de origem migrante.

Teatro turco-alemão, pós-migração, transculturalidade.
After the second world war a lack of labour work in Germany caused migration agreements with various countries to occupy jobs there. Great part of the migrants came from Turkey. In the 1950s and 60s the Turkish cultural production was not visible for the German society, but slowly a certain production of films and cabarets appeared. From the 1980s on, theatre started to bring migrant themes regarding mostly the sociocultural context. The juvenile theatre regarded the migration theme with clichés related to the youngsters's religion or criminality. Only in 2008, when Shermin Langhoff assumed the Ballhaus Naunynstrasse theatre in Berlin, did the theatre begin to reflect the social reality of Germany as a country of immigration: the established habits of the public and the conventional points of views were questioned by post migrant directors, who were mostly already in the third generation living in Germany. Slowly the professional German theatre scene begins to open up for German dramaturgs and actors of migrant roots.

Keywords

Turkish-German theater, post-migration, transculturality. 
Desde o início dos anos 1950, já se podia perceber, na Alemanha, a falta de mão de obra, principalmente na mineração e na indústria: a população na República Federal da Alemanha não acompanhava o crescimento do mercado de trabalho. Deste modo, foram recrutados trabalhadores e trabalhadoras de outros países: o primeiro "Acordo para a contratação e intermediação de mão de obra italiana para a República Federativa da Alemanha" - dos chamados Acordos de Recrutamento - foi assinado em 1955, com a Itália. Outros países a seguiram: em 1960, a Grécia e a Espanha; em 1961, a Turquia; em 1963, Marrocos; em 1964, Portugal; em 1965, Tunísia e em 1968, a lugoslávia. Com a Turquia, foi planejado um "princípio de rotação", no qual os trabalhadores e trabalhadoras deveriam ser "substituídos" por novos imigrantes, após um período de dois anos de contrato de trabalho. Muitos, porém, permaneciam na Alemanha, ainda que com as malas prontas, e mesmo antes de trazer o marido ou esposa, traziam a sua cultura explicitada nas ações que praticavam em suas mercearias, bares e eventos culturais típicos. Ainda que o teatro turco-alemão tenha surgido já nos anos 1960, esta atividade cultural de trabalhadores imigrantes não só não foi percebida pela maior parte da população, como tampouco a sua necessidade de atividades culturais (BORAN, 2004a). "Afinal, os turcos não vieram para Alemanha para fazer teatro, mas para trabalhar" (idem, 2004b, p. 88) diz o produtor teatral Mürtüz Yolcu.

A diferenciação da vida turca (e suas produções culturais) só se impregnou, superficial e tardiamente, na consciência da sociedade alemã. Além disso, a perspectiva dominante daquele tempo reduzia os turcos à mão de obra sem reivindicações sociais ou culturais. (ibid., p. 106)
Entre eles, havia também imigrantes do meio acadêmico e urbano, como o autor e ator Aras Ören, que se ocupou com a teoria e a prática do teatro turco-alemão.

Com o movimento dos trabalhadores, nos anos 1970, o teatro turco na República Federativa Alemã se politizou, colocando-se na tradição do teatro agitprop (teatro político). Em 1984, foi criado no Tiyatrom, em Berlim, o primeiro espaço fixo para apresentações em língua turca.

Nesse período, alguns diretores alemães, como Rainer Werner Fassbinder, Peter Stein e Frank Castorf, passaram a narrar histórias, no início dos anos 1980 e 1990, pela perspectiva dos imigrantes:

No inicio dos anos 1980, no antigo Teatro am Halleschen Ufer, Peter Stein foi o primeiro a ser reconhecido, na paisagem teatral da Alemanha, por encenar com artistas exilados políticos, e por fazer experimentações com histórias, partindo da perspectiva de imigrantes. Antes disso, a história do teatro de 'migrantes' na Alemanha acontecia em pequena escala, estimulada por esforços de integração e marcada por suas condições socioculturais ou semiprofissionais. (LANGHOFF, 2009, p. 130)

Diretores de origem estrangeira quase não apareciam nesta época na indústria cultural alemã, apesar da cultura de migração não estar presente só nos grandes centros urbanos. Ainda que tenha se formado na Alemanha uma classe média de imigrantes, recebendo pessoas de diferentes países e por diferentes causas, esta realidade social não se transportou para o teatro. Com efeito, uma atriz ou um ator que não correspondesse à aparência esperada pelos consumidores de cultura alemães, frequentemente só encontrava espaço para atuar, em filmes ou no teatro, como garçom turco, traficante negro ou empregada 
doméstica. O tema da migração estava se fortalecendo apenas em peças infantis e juvenis, como no Teatro Grips, ou, nos anos 1990, nas peças juvenis de Lutz Hübner.

Porém, as histórias eram narradas, na maioria das vezes, sob o ponto de vista alemão e serviam a objetivos didáticos, encostando nas bordas do clichê. No cerne da ação, havia um assassinato por honra ou a submissão de muIheres - a diversidade da identidade imigrante e o seu meio, praticamente, não eram levados em consideração. Em meados dos anos 1980, o cabaré turco alemão já encontrava uma larga escala de seguidores alemães. Nos anos 1990, começa o desenvolvimento do cinema turco alemão e Fatih Akin ganha o Urso de Ouro no Festival de Cinema de Berlim (Berlinale) com Gegen die Wand (Contra a parede). No entanto somente em 2008 institucionalizouse um teatro que trata da perspectiva pós-migrante, dirigido a um público multicultural, com a criação do Ballhaus Naunynstrasse ${ }^{1}$, no qual eu trabalhei por três anos como dramaturgista. O ponto de partida da perspectiva alemã-turca foi dado sob a direção artística de Shermin Langhoff, partindo da história da imigração no bairro berlinense de Kreuzberg e da rede de apoio "Salto Cultural", formada por Shermin Langhoff, pelo dramaturgista Tunçay Kulaoglu e pela cineasta Martina Priessner. Festivais e intercâmbios artísticos iranianos, que discutiam a Revolução Árabe, também integravam a programação, ao lado de outros temas sobre transculturalidade. Com a adesão de Wagner Carvalho, os componentes afro-alemães e a dança contemporânea passaram a figurar em sua linguagem estética. Carvalho foi, por muitos anos, curador do Festival de Dança Brasil move Berlim, no Teatro am Hallesches Ufer, e hoje é diretor do Ballhaus Naunynstrasse.
O conceito "pós-migrante" surgiu na teoria literária anglo-americana e está agora presente na cena cultural da Alemanha: o Ballhaus Naunynstrasse oferece aos artistas de origem estrangeira um fórum para narrar histórias a partir de seus pontos de vista, e levá-las ao palco ${ }^{2}$. Segundo Shermin Langhoff, o conceito de "pós-migrante abarca sobretudo a história e a perspectiva daqueles que já não são imigrantes, mas trazem o histórico da migração como saber pessoal e memória coletiva" (LANGHOFF in TIGGES e PELKA. 2011, p. 399 e s.) Em 2004, Langhoff inaugurou o Festival Beyond Belonging (Além do Pertencimento), no Teatro am Hallesches Ufer, em Berlim, e trabaIhou junto a artistas pós-migrantes como Ayse Polat, Neco Çelik, Feridun Zaimoglu, Emine Sevgi Özdamar e Kanak Attak. Em 2006, comemoraram o seu primeiro grande sucesso: Virgens de Preto (Schwarze Jungfrauen) de Feridun Zaimoglu e Günter Senkel, dirigido por Neco Celik e convidado para o Festival de Teatro de Müllheim. O texto teatral é baseado em entrevistas com mulheres islâmicas residentes na Alemanha. São monólogos sobre suas vidas, suas ideias sobre política, sexualidade e Islã, apresentando diferentes facetas da visão feminina do cotidiano na religião e na cultura. Com isso, são oferecidas, à maioria da população alemã, visões, até então, desconhecidas, perspectivas muito diferenciadas do cotidiano do imigrante, que vão além do clichê da "menina com lenço na cabeça".

Depois do sucesso das Virgens de Preto, Neco Çelik trabalhou como diretor no Teatro de Câmera de Munique, no Teatro Oberhausen e na Ópera Municipal de Stuttgart. Desde a inauguração do Ballhaus Naunynstrasse, puderam progredir as carreiras de diretores e diretoras, e também de atores e atrizes, que

\footnotetext{
${ }_{1}^{1}$ Ballhaus Naunynstrasse, literalmente Salão de Baile da Rua Neunyn. O teatro ocupou o prédio onde havia um salão de baile muito frequentado nos anos de 1920, em Berlim. (N. do T.)

2 Ver: www.ballhausnaunynstrasse.de (2009) (nota da autora)
} 
fizeram a sua estréia no beyond belonging ou no Ballhaus Naunynstrasse. A frente deste grupo está Nurkan Erpulat, que estudou direção na Escola de Atores Ernst Busch e encenou diversas peças em Berlim, no Ballhaus Naunynstrasse e no Teatro am Hallesches Ufer. Em 2011, ele foi convidado para apresentar Sangue Louco (Verrücktes Blut) no Encontro de Teatro de Berlim, o mais importante festival de teatro da Alemanha, e foi eleito pela crítica do Theater Heute ${ }^{3}$ como Melhor Diretor da Nova Geração, tornando-se, em seguida, diretor residente do Teatro de Düsseldorf. O enredo de Sangue Louco enfoca a relação entre alunos migrantes e uma professora alemã de uma perspectiva não convencional: não é uma peça juvenil que pretenda representar alunos e alunas, mas sim, uma crítica ao discurso da educação burguesa sobre escola e integração. Erpulat segue o desejo da política educacional conservadora de uma "mão forte" e o leva ao absurdo: sob a mira de uma arma, os alunos são obrigados a recitar Schiller.

Aquilo que as peças no Ballhaus Naunynstrasse têm em comum não é a estética, mas sim, o conteúdo. Há diferentes tipos de direção, abordagens estéticas e conceitos. As histórias são narradas a partir do ponto de vista do diretor ou diretora e dos participantes. Diretores, como Hakan Savas Mican, começaram no Ballhaus e encenam agora também em outras casas. Mican veio do meio cinematográfico e escreveu algumas das peças que ele mesmo encenou. Nas suas direções, percebe-se o pensamento cinematográfico, os lugares se manifestam no palco pelo contexto e, com um tratamento minimalista dos ade- reços, suas histórias descrevem instantes do cotidiano, marcados pelas referências sociais dos protagonista. Sua primeira encenação fora do Ballhaus Naunynstrasse foi a peça Katzelmacher $^{4}$ de Fassbinder, no Teatro Municipal de Mainz, no outono de 2012. No inicio da estação teatral de 2013/2014, Shermin Langhoff em conjunto com o dramaturgista Jens Hillje assumiram a gestão do Teatro Maxim Gorki, e Tunçay Kulaoglu e Wagner Carvalho começam a dirigir o Ballhaus Naunynstrasse.

Iniciando com o discurso sobre o tema da interculturalidade (Terkessidis, 2010) e imigração nas ciências humanas e culturais - e sobretudo causado pelo debate político da integração - desde então, diversos profissionais de teatros municipais e estaduais, além de grupos independentes, colocaram em cena histórias e protagonistas da imigração. Desde 2005, a oficina para dramaturgos, Wortstaetten de Viena, premia um projeto internacional de autores teatrais e confere, anualmente, o Prêmio de Dramaturgia de Exílio a autores que escrevem em alemão e se debruçam sobre o tema da identidade e da interculturalidade. Entre os premiados, está a autora Marianna Salzmann, cuja a peça Mameloschn, língua mãe (Muttersprache Mameloschn5) ganhou, em 2013, o Prêmio do Júri Popular no Festival de Teatro de Müllheim, e a autora Olga Grjasnowa, conhecida através do romance $O$ russo é alguém que ama péculas (Der Russe ist einer, der Birken liebt). O Teatro de Colônia, ainda em 2007, sob a direção geral de Karin Beier, também tentou trazer a realidade social da cidade, reservando um terço das vagas da companhia para atores e atrizes (pós)

\footnotetext{
${ }^{3}$ Revista especializada alemã (N. do T.)

${ }^{4}$ Katzelmacher é uma palavra pejorativa e pouco usada para imigrantes (N. do T.)

${ }^{5} \mathrm{O}$ texto está traduzido para português e se encontra no biblioteca de teatro do Instituto Goethe. Disponível em: http://www. goethe.de/kue/the/nds/nds/bib/ptindex.htm
} 
migrantes. Na mesma esteira, também os teTraduzido por Elisa Ramalho Ortigão6 atros municipais de tamanho médio, como o Teatro de Bremerhaven ou o Teatro de Krefeld -Mönchengladbach demonstram em festivais, peças, intercâmbio de direções e na formação da companhia teatral que, também na província, é possível uma confrontação com o teatro pós-migrante e as facetas relativas à história alemã e à realidade atual.

BORAN, Erol M. Eine Geschichte des türkischdeutschen Theaters und Kabaretts. Dissertação. Ohio: Editora Ohio State University, 2004.

LANGHOFF Shermin. "Postmigrantisches Theater?! Das Experiment Ballhaus Naunynstraße in Berlin", in BAYER et al: Crossing Munich. Orte, Bilder und Debatten der Migration. Munique: Editora Schreiber, 2009.

KASTNER Barbara, LANGHOFF Shermin, KULAOGLU Tuncay. "Migration dichten und deuten. Ein Gespräch zwischen Shermin Langhoff, Tuncay Kulaolu und Barbara Kastner", in TIGGES e PELKA. Das Drama nach dem Drama. Editora Transcript Bielefeld, 2011.

TERKESSIDIS, Mark. Interkultur. Berlim: Editora Suhrkamp, 2010.

\section{Recebido em 14/06/2016 \\ Aprovado em 18/06/2016}

6 Pesquisadora DCR Fapes-CNPq na UFES, doutora em Literatura Comparada pela UFF, mestre em Ciência da Literatura pela UFRJ. Atua na área de teoria da arte, teoria da literatura, cultura e literaturas alemães, literatura brasileira, cultura popular e tradução. 